\title{
NÍVEL DE EDUCAÇÃO FINANCEIRA CONSTATADO ENTRE UNIVERSITÁRIOS RECÉM-INGRESSOS EM CIÊNCIAS CONTÁBEIS
}

\author{
Francisco José Mateus Santana ${ }^{1}$; Darlan Oliveira Bezerra ${ }^{2}$; Valfredo Mateus \\ Santana $^{3}$; Walleska dos Anjos Oliveira ${ }^{1}$ \\ ${ }^{1}$ Graduandos em Ciências Contábeis / Instituto de Educação Superior da Paraíba, \\ João Pessoa, Paraíba (fco.mscontabilidade@gmail.com) \\ 2Professor do curso de Ciências Contábeis / Instituto de Educação Superior da \\ Paraíba, João Pessoa, Paraíba \\ ${ }^{3}$ Graduado em Ciências Sociais e Jurídicas / Universidade Federal de Campina \\ Grande, João Pessoa, Paraíba
}

Recebido em: 02/10/2017 - Aprovado em: 21/11/2017 - Publicado em: 05/12/2017 DOI: 10.18677/EnciBio_2017B103

\begin{abstract}
RESUMO
Este trabalho objetivou avaliar o grau de compreensão de discentes ingressantes no curso de ciências contábeis de uma Instituição de Ensino Superior (IES) em João Pessoa, Paraíba, acerca do tema educação financeira. A coleta de dados foi realizada através de um questionário, aplicado nos meses de março a abril de 2017, contendo 15 questões, que contemplavam enunciados sobre os perfis dos discentes recém-ingressos no curso de ciências contábeis, de ambos os sexos e com idades até 40 anos. As questões estavam decompostas em três grandes grupos que englobavam tópicos sobre o grau de segurança dos discentes sobre o assunto, bem como o nível de conhecimento prático relacionado e o perfil sócio-econômico. Nos principais resultados, $52,27 \%$ dos discentes revelaram como nada seguros ou não muito seguros para gerir seu próprio recurso e apenas 9,09\% como totalmente seguros. Tendo este resultado influenciado os itens relacionados ao conhecimento prático. Além disso, $52,27 \%$ dos discentes eram formados por homens, $86,36 \%$ apresentavam idades com até 30 anos e 77,27\% apresentavam alguma ocupação laboral, apesar de $61,36 \%$ ainda residirem com os pais. É evidente que a educação financeira é um assunto de fundamental importância para a sistematização de uma população, dos quais o propósito principal é satisfazer as demandas individuais, familiares e até empresariais. Assim, este estudo tornou-se relevante devido à capacidade de validar, por meio das respostas obtidas, como a ausência de entendimento sobre o assunto pode afetar na tomada de decisões futuras.
\end{abstract}

PALAVRAS-CHAVE: Comportamento financeiro; Finanças pessoais; Formação. 


\title{
OBSERVED FINANCIAL EDUCATION LEVEL AMONG NEWLY ENTERED COLLEGE STUDENTS OF THE ACCOUNTING COURSE
}

\begin{abstract}
This work aimed to evaluate the comprehension level of the newly entered students of the accounting course of a tertiary level institution in João Pessoa, Paraíba, on the topic of financial education. The data gathering was made through a survey, applied in the months of March and April 2017, containing 15 questions that covered assertions on the profiles on the newly arrived students of the accounting course, from both sexes and until the age of 40 . The questions were divided in three great groups that covered topics on the degree of security of the students on the subject, as well as the related practical knowledge and the socioeconomic profile. In the main results, $52.27 \%$ of the students appears as not secured or not much secured to manage their own resources and only $9.09 \%$ as totally secured, with this resulting influencing the items related to practical knowledge. Furthermore, $52.27 \%$ of the students were male, $86.36 \%$ had less than 30 years and $77.27 \%$ had some occupation, although $61.36 \%$ lived with their parents. It's evident that the financial education is a highly important subject for the systematization of a population that has as a main purpose satisfy the individual, family and enterprising demands. So, this study became relevant because of the capacity of validating through the obtained answers, like the lack of understanding the subject affecting the future decisionmaking.
\end{abstract}

KEYWORDS: Financial behavior; Formation; Personal finances.

\section{INTRODUÇÃO}

Um dos motivos de preocupação com a educação financeira está ligado ao passado histórico e cultural do Brasil, onde havia uma alternância comumente de inflação, onde preços variavam muito rápido, aliado ao valor de moeda diferente, fatores estes que por muito tempo foram traços da economia. Neste quesito, o cidadão era tomado por decisões rápidas e de caráter não tão eficaz, sem uma planificação merecida. Ao final dos anos 90, com o descerramento econômico, e com a consolidação da moeda em 94, colaboraram para que a inflação estabilizasse e que os brasileiros conseguissem projetar sobre como gerir melhor suas finanças, proporcionando assim, um processo de transição cultural. Houve um incremento do poder de compra, do crédito e um estiramento dos períodos de financiamento, além de maior autonomia do indivíduo. Diante disso, ocorreram mudanças significativas e a individualidade qualitativa de tomada de decisões passaram a influenciar toda economia, tornando-se necessário saber se planejar por longo prazo (VIEIRA et al., 2011; SILVA et al., 2016; MOUNA; ANIS, 2017).

Sendo assim, se fez necessário abordar de forma significativa o tema educação financeira para a sociedade, visto que este assunto já é bastante discutido em diversos países, no dia a dia de entidades privadas, e um pouco menos comum dentre a população brasileira (VIEIRA et al., 2011), tornando-se uma medida de caráter imprescindível para que os indivíduos desenvolvam competência para tomada de decisões com embasamento em termos de organização financeira. Uma vez obtido este conhecimento, 0 indivíduo consegue se incluir no mundo contemporâneo de forma mais precavida (SAVOIA et al., 2007; VAN ROOIJ et al., 2012; LO PRETE, 2013; ANGULO-RUIZ; PERGELOVA, 2015; GIOFRÉ, 2017).

Fez inevitável também adaptar-se às inovações da sociedade, não obstante, ainda, o surgimento das novas tecnologias. Da forma veloz em que a sociedade 
evolui, urge com desafio a eficácia e a singularidade da tomada de decisões, em que os gestores exerçam papel fundamental nesse processo. Sendo de substancial valor que os mesmos, e também cada indivíduo, necessitem estar interligados e à disposição para enfrentar esse meio em transformação (VIEIRA et al., 2011).

Nessa continuidade, a interação entre o âmbito político, empresarial, e a sociedade, a sumidade é planificar acertadamente os atos em futuro não próximo, tomando certas precauções onde poupar é preciso, minorar despesas dispensáveis, entender as diversidades de créditos oferecidos e dominar a tecnologia para a execução de operações financeiras de maneira correta (SAVOIA et al., 2007).

O conhecimento em finanças pessoais aumenta a aptidão para facilitar decisões convenientes, a ponto de auxiliar numa boa administração dos recursos, facilitando a ascensão pessoal em um mercado competitivo. No Brasil, o assunto abordado não acentuou proporções maiores como visto em outros países. Sobremaneira, o que existem são iniciativas de entidades públicas e privadas que colaboram para o conhecimento, mas distante da instrução necessária para decisões de mercado e negócios (VIEIRA et al., 2011; VAN ROOIJ et al., 2012).

Há um cenário preocupante sobre o tema educação financeira no Brasil, solicitando uma urgência na introdução do tema em várias esferas, considerando ainda a heterogeneidade da repartição de renda do país, onde maior parte da riqueza produtiva é direcionada ao estado, sendo de fundamental importância a perfeição na gestão do recurso individual. Logo, esforços e monitoramento do setor na coordenação de projetos são necessários, mas aliado a isso, para o fortalecimento duradouro da educação financeira as instituições de ensino tornam-se relevantes para o sucesso do tema (SAVOIA et al., 2007; LO PRETE, 2013).

$O$ ensino financeiro, de maneira geral, se tornou uma ferramenta importante como complemento do seguimento de mercado, da normatização prudencial e aperfeiçoamento da cultura financeira dos indivíduos, sendo prioridade a longo prazo em alguns países. Por exemplo, foi desenvolvido pela OECD/INFE, ferramentas para dar suporte a políticos e autoridades na implementação de estratégias pátrias de educação financeira, como os princípios de alto nível sobre estratégias Nacionais de Educação Financeira. Em 2015, foi lançado o Manual de Políticas da OECD/INFE, cujo manual assiste os governos e as partes interessadas para enfrentar a realização de um plano de educação financeira. Esse manual oferece um aspecto global das estratégias no mundo, um diagnóstico das condutas e as lições aprendidas (OECD, 2017; MOUNA; ANIS, 2017; GIOFRÉ, 2017).

No Brasil, é necessária uma maior discussão sobre o tema, já que há um plano de educação financeira, promovido pela criação de normas para sinalizar iniciativas efetivas, seja do Governo, da disposição privada ou sociedade civil; 45 países, em 2013, de diversos níveis de renda, geraram inúmeros projetos relacionados ao assunto, através de convenções mundiais e regionais a exemplo do G20 e a Cooperação econômica Ásia-Pacífico (APEC) que demonstraram como são importantes as diligências nacionais de educação financeira conferir um equilíbrio entre a estabilidade econômico-financeira e a prosperidade social (ENEF, 2017).

Perante essa perspectiva, este trabalho avaliou o nível de instrução de discentes recém-ingressos no curso de ciências contábeis de uma IES em João Pessoa, Paraíba, acerca do tema educação financeira. Analisou-se, puramente o grau de entendimento sobre concepções relacionadas a educação financeira, tomada de decisões, e uma análise do perfil sócio econômico dos discentes. 


\section{MATERIAL E MÉTODOS}

Como será constatada a sistemática impressa na viabilização deste estudo, não abdicou de uma apreciação documental e bibliográfica da literatura vigente, substancialmente do trabalho elaborado por VIEIRA et al., (2011), complementado de uma busca por outros estudos similares relativos a educação financeira no Brasil. Recorreu-se também a estudos da literatura internacional, que salientavam em suas conclusões valores expressivos a respeito da educação financeira e a importância dela para o encadeamento de tomada de decisões.

\section{Tipo de pesquisa, coleta e análise dos dados}

Tratando-se de um estudo de caso onde foi usado um questionário (vide anexo I) aos alunos de contabilidade do Instituto de Educação Superior da Paraíba (IESP), em João Pessoa, Paraíba, as perguntas do questionário aplicado foram decompostas em três grupos que englobavam questões sobre o grau de segurança do discente sobre o assunto tema deste estudo, bem como o nível de conhecimento relacionado a educação financeira e o seu perfil socioeconômico (Figura 1).

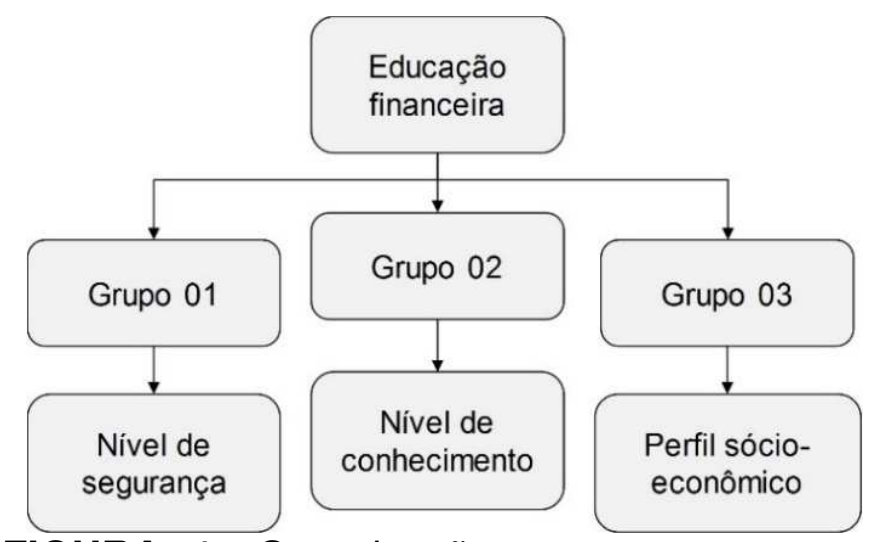

FIGURA 1. Organização em grupos, para interpretação específica.

A coleta de dados através de questionários contemplou discentes do primeiro período do curso de ciências contábeis, que totalizavam 44 alunos, de ambos os sexos e com idades até 40 anos. Os dados foram apresentados de forma legítima, não disfarçada, sendo aplicado o mesmo questionário para todos os discentes e realizada a pesquisa nos meses de março a abril de 2017. Os dados foram tabulados e analisados por meio de distribuição de frequência utilizando planilha eletrônica Excel e os gráficos produzidos em ambiente Origin.

\section{Distribuição das questões}

O questionário justaposto continha 15 questões que foram adaptadas de VIEIRA et al., (2011) visando o seguinte escopo: na questão um, foi avaliada a percepção dos discentes quanto ao nível de instrução acerca da educação financeira e sua autoconfiança para tomada de decisões. Na questão dois avaliou-se como foram obtidos os conhecimentos dos questionados sobre o tema, levando em consideração que para um melhor aprendizado, não se pode basear por apenas uma só fonte, mas também de experiências ao longo da vida.

Visando atender ao objetivo particular que pretendia constatar o nível de entendimento sobre conceitos ligados a educação financeira, sendo assim, foram aplicadas as perguntas três a seis do questionário. A questão três avaliou se os 
entrevistados tinham consciência que investimentos possuem distintos graus de liquidez. Já a questão quatro avaliou a aplicação na prática de uma teoria importante de finanças, que com o tempo o dinheiro apresenta valor diferente.

A questão cinco avaliou se os entrevistados possuíam noção de que obrigações têm custos sobressalentes, onde era identificado que dívidas postergadas representam pagamentos mais elevados. E a questão seis avaliou se os interrogados entendiam os conceitos de planejamento financeiro e de poupança. Além disso, foi avaliado o contexto sócio-econômico dos entrevistados para que pudesse ser correlacionado com todas as outras respostas apresentadas, dessa forma foram aplicadas as perguntas sete a 15 do questionário.

\section{RESULTADOS E DISCUSSÃO}

\section{Nível de segurança dos discentes}

As questões um e dois visavam compreender o nível de segurança dos discentes sobre o assunto e também entender de onde vem o conhecimento obtido para gerir suas finanças. Quanto ao nível de segurança para gerir seu dinheiro, questão um, 52,27\% dos discentes se julgam nada seguros ou não muito seguros, ao passo que apenas $9,09 \%$ se mostraram como muito seguros para conduzir seus recursos (Figura 2). O conhecimento financeiro, em particular, é importante por capacitar os jovens para controlar a sua situação financeira. Dessa maneira, podese esperar que o conhecimento financeiro apresente um impacto positivo sobre 0 comportamento financeiro responsável (ANGULO-RUIZ; PERGELOVA, 2015).

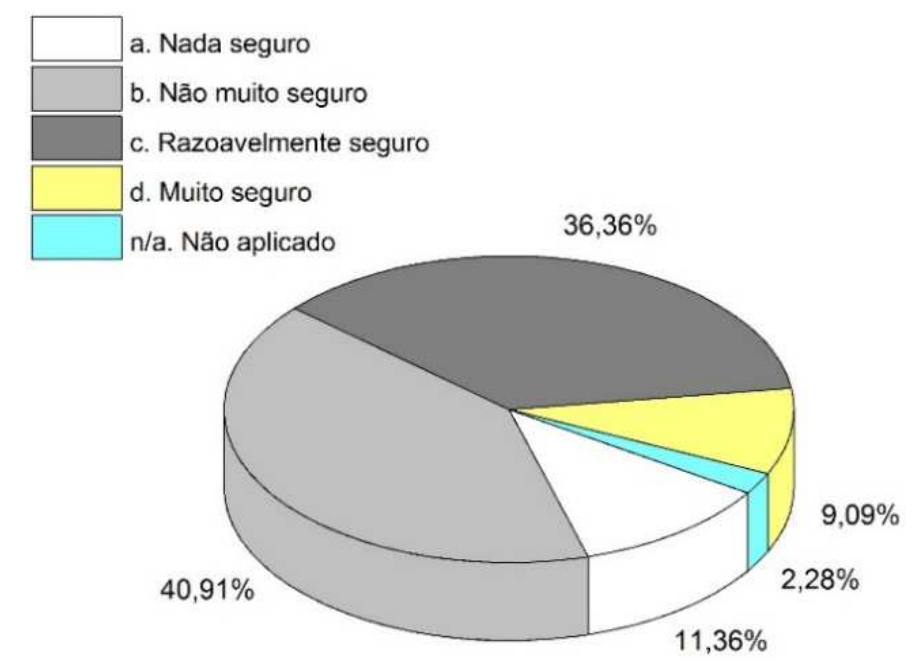

FIGURA 2. Nível de segurança para gerir seu dinheiro.

Com a questão dois, verificou-se a origem dos conhecimentos adquiridos para controlar seu dinheiro (Tabela 1). Destes, $52,27 \%$ dos respondentes afirmaram ter instrução adquirida em aulas na universidade, a fonte mais importante, enquanto que $2,27 \%$ declararam que as aulas em universidade possuíam baixa importância. Outros $36,36 \%$ afirmaram terem adquirido instrução no que tange à educação financeira junto à família como a fonte mais importante. 
TABELA 1. Onde foi assimilado conhecimento para gerir recurso próprio.

\begin{tabular}{cccccc}
\hline \multirow{2}{*}{ Respostas } & $\mathbf{5}$ & $\mathbf{2}$ & $\mathbf{3}$ & $\mathbf{4}$ & $\mathbf{n} / \mathbf{a}$ \\
\cline { 2 - 6 } & $\mathbf{1}$ & 18,18 & 34,09 & 4,55 & 6,82 \\
\hline Em casa com a família & 36,36 & 31,82 & 40,91 & 4,55 & 6,82 \\
De conversas com amigos & 15,91 & 31,64 & 18,18 & 2,27 & 13,64 \\
Em aulas na universidade & 52,27 & 13,64 & 18,27 & 9,09 & 15,91 \\
De revistas, livros, TV e o rádio & 15,91 & 31,82 & 27,27 & 9 \\
De minha experiência prática & 34,09 & 18,18 & 36,36 & 2,27 & 9,09 \\
\hline 1 = mais importante; 2 = importância média-alta; $3=$ importância média; $4=$ importância \\
baixa; n/a = não aplicado.
\end{tabular}

A família contribui para o fortalecimento dos discentes através dos valores que exibem e incutem em seus filhos, de modo que a exibição de boas habilidades de gerenciamento do dinheiro se alinhe à situação financeira da família, isto de uma forma pró-ativa (ANGULO-RUIZ; PERGELOVA, 2015).

Foi observado que uma parcela importante dos discentes, 40,91\%, afirmaram que a discussão entre amigos tem importância média. 34,09\% refutaram que a experiência prática tem maior responsabilidade em seu conhecimento, enquanto que $2,27 \%$ admitiram ter baixa importância. Além disso, $15,91 \%$ anunciaram que os meios de comunicação sejam em revistas, livros, TV e rádio são os mais importantes, ao passo que 9,09\% avaliaram como de baixa importância.

Em síntese, as conclusões extraídas destas apreciações é que existem diversas formas de expandir o conhecimento a respeito da proposição estudada, que não está ligada a um único meio de transmissão, mas da forma que os interlocutores transformam tais informações em entendimento (que pode ser de maneira diversa).

\section{Nível de conhecimento prático aplicado à educação financeira}

A educação financeira visa um melhor comportamento financeiro e maturidade na tomada de decisões do dia a dia. A questão três trilhava o conceito de liquidez dos ativos, em que 50\% acertadamente marcaram a alternativa desejada. A alternativa correta é a letra d, pois é a que representava menor liquidez, como bens móveis e imóveis, onde as outras alternativas mostravam ativos de maior liquidez. Ademais, $31,82 \%$ assinalaram a alternativa "a", poupança e fundo de investimento como mais rápida liquidez e 11,36\% para ações ou dólar (Tabela 2).

TABELA 2. Sobre o conceito de liquidez de ativos.

\begin{tabular}{ccc}
\hline Alternativas & Respostas & $\%$ \\
\hline a & Poupança ou Fundos de Investimento & 31,82 \\
b & Ações ou Dólar & 11,36 \\
c & Conta-corrente & 6,82 \\
d & Bens (Carro, moto, imóvel...) & 50,00 \\
e & n/a & - \\
\hline
\end{tabular}

n/a = não aplicado.

$\mathrm{Na}$ questão quatro que tratava do valor do recurso com o tempo, assim como uma ligação positiva entre a clareza do saber que dinheiro, no passado, não possui o mesmo valor hoje ou amanhã, apontou um grau de acerto em $47,73 \%$ (Tabela 3). Logo, a alternativa correta era a letra c na qual o questionado identifica que, mesmo valores aplicados em momentos diferentes, tem saldo futuro distintos. Uma parcela 
de $40,91 \%$ dos discentes colocaram como correta a letra "a", não levando em conta alguns conceitos básicos que, em geral, estes foram o que responderam como menos seguro na questão que dimensiona o grau de segurança do entrevistado.

TABELA 3. Sobre o valor do recurso no tempo.

\begin{tabular}{ccc}
\hline Alternativas & Respostas & $\%$ \\
\hline a & $\begin{array}{c}\text { Eles teriam o mesmo valor, já que na } \\
\text { prática guardaram as mesmas somas }\end{array}$ & 40,91 \\
b & $\begin{array}{c}\text { Ronaldo, porque poupou mais a cada ano } \\
\text { Daniela, porque seu dinheiro rendeu por }\end{array}$ & $\begin{array}{c}11,36 \\
\text { mais tempo a juros compostos. }\end{array}$ \\
d & n/a & - \\
\hline
\end{tabular}

$\mathrm{n} / \mathrm{a}=$ não aplicado.

Foi tido como alto o nível de acerto desta questão, que pode ser correlacionado ao conhecimento adquirido pelos discentes em disciplinas relacionadas já na universidade, o que indica um ponto positivo sobre a compreensão do tema. Habilidades sobre o gerenciamento do dinheiro são importantes determinantes de resultados financeiros (FRENCH; MCKILLOP, 2016).

A questão cinco avaliou como os discentes pensavam a respeito de dívidas e seus custos financeiros associados (Tabela 4). O grau de acerto desta questão foi de $59,09 \%$, que pode estar associado ao conhecimento adquirido na universidade e atestados pelas respostas dadas nas questões anteriores, mesmo que de forma menos categórica. Observou-se que 20,45\% ainda dos discentes marcaram como correta a letra "a", o que demonstra uma fragilidade de conhecimento sobre o tema.

TABELA 4. Sobre dívidas e seus custos financeiros associados.

\begin{tabular}{ccc}
\hline Alternativas & Respostas & $\%$ \\
\hline a & Ellen, que sempre paga todo o saldo do cartão de & crédito no vencimento. \\
& \multicolumn{2}{c}{$\begin{array}{c}\text { Pedro, que geralmente paga todo o saldo do cartão } \\
\text { de crédito no vencimento, mas ocasionalmente paga } \\
\text { só o mínimo, quando está sem dinheiro. }\end{array}$} \\
b & $\begin{array}{c}\text { Luís, que paga pelo menos o mínimo todo mês e um } \\
\text { pouco mais quando tem alguma folga. }\end{array}$ & $\begin{array}{c}11,36 \\
\text { C }\end{array}$ \\
d & Nanci, que sempre paga o mínimo & 59,09 \\
e & n/a & 4,55 \\
\hline $\mathrm{n} / \mathrm{a}=$ não aplicado. & &
\end{tabular}

Apesar disso, na questão seis, foi notada a consciência de planejamento fazendário dos pesquisados, o grau de acerto foi de $84,09 \%$, onde o número de assertividade foi elevado, mostrando conhecimentos básicos de noções financeiras (Figura 3), que, não obstante, todos os entrevistados responderam a questão. 


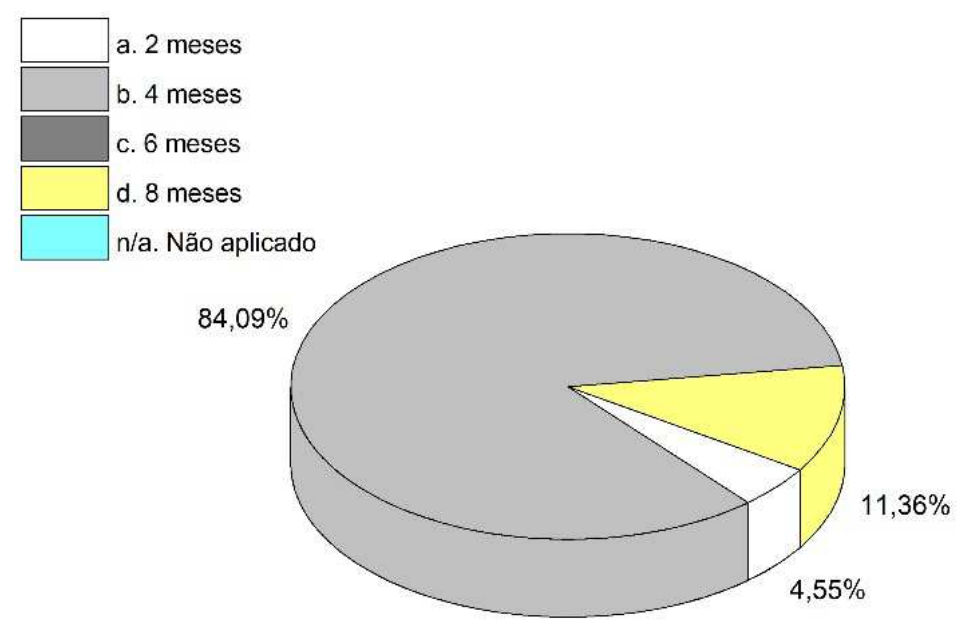

FIGURA 3. Consciência sobre o planejamento fazendário dos pesquisados.

Dada às mudanças dinâmicas no ambiente econômico, especialmente nos mercados financeiros, a necessidade de melhorar o conhecimento dos indivíduos sobre o tema torna-se uma medida fundamental (MOUNA; ANIS, 2017). No Brasil, em 2011, foi criada, através do Decreto Federal 7.397/2010, a Estratégia Nacional de Educação Financeira - ENEF, uma mobilização multissetorial em torno da promoção de ações de educação financeira no Brasil, com o objetivo de contribuir para o fortalecimento da cidadania ao apoiar ações que ajudam a população a tomar decisões financeiras autônomas e conscientes (SILVA et al., 2016).

\section{Perfil sócio-econômico}

Os dados levantados revelaram o perfil sócio-econômico dos entrevistados, por características individuais assimiladas pela presente pesquisa. $O$ perfil dos entrevistados é estabelecido por turma mista estruturadas com $52,27 \%$ de homens e $47,73 \%$ de mulheres, cuja idade é dada em percentual para pessoas de até 30 anos em $86,36 \%$. Ao pensar a respeito de um público levemente maior formado por homens, o expressivo valor referente ao público feminino mostra uma ampla inserção das mulheres na área contábil.

O estado civil é constituído por $75 \%$ solteiros e $18,18 \%$ de casados. O perfil de alunos que trabalham está exposto em grande parte dos entrevistados, sendo que $77,27 \%$ possuem ocupação, $70,45 \%$ emprego formal, 6,82\% informal, 15,91\% não trabalha e $6,82 \%$ tem outros tipos de afazeres. Avaliados mais a frente, com quem residem, declaram que $61,36 \%$ moram com os pais, e os demais com filhos, cônjuges e outros. Quanto ao grau de escolaridades dos pais, 6,82\% tem apenas o fundamental, $27,27 \%$ concluíram o ensino médio e 31,82\% possuem superior completo e pós-graduação. A melhoria da educação financeira pode fazer uma diferença significativa no comportamento financeiro, sobretudo para discentes cujo a família possui maior grau de escolaridade (DISNEY; GATHERGOOD, 2013).

As rendas pessoais dos questionados são concentradas nas faixas de menor rendimento, onde $54,55 \%$ ganham até $R \$ 1.000,00$ por mês, e $29,55 \%$ ganham no máximo $\mathrm{R} \$ 500,00$ mensal. No momento em que são consideradas rendas familiares, é concentrado em uma faixa maior, em que $72,73 \%$ dos familiares tem renda até $R \$ 4.000,00$ reais e $20,46 \%$ tem renda inferior a $R \$ 1.500,00$ ao mês. Vários estudos relatam sobre a relevância da educação financeira no nexo das finanças-desigualdade. Tem-se constatado que a desigualdade de renda cresce menos onde a educação financeira é maior; e que o desenvolvimento financeiro 
estar atrelado a este fator. A capacidade de se beneficiar de investimentos, por exemplo, depende do nível de educação financeira (LO PRETE, 2013).

\section{CONCLUSÃO}

No que tange ao estudo obtido, nota-se que foram exploradas noções fundamentais sobre o tema educação financeira. Assim, o estudo elaborado reafirmou o posicionamento sistemático da educação financeira e que na atualidade não é possível se dissociar o conhecimento técnico, da escassez da sabedoria formada sobre o assunto. Os resultados apresentados neste artigo colaboraram com a carência de estudos sobre o tema, apresentando um atual notar do conteúdo.

Em geral os discentes apresentaram bom nível de assertividade nas questões práticas sugeridas em questionário, deixando claro que a formação acadêmica coopera para melhoria acerca de decisões no campo financeiro. Conquanto, existem áreas a serem estudadas além da acadêmica, como a experiência prática, batepapo com colegas e familiares, que em pesquisas futuras podem ser aprofundadas.

A educação financeira é um assunto de fundamental importância para a sistematização de uma população, dos quais o propósito principal é satisfazer sobretudo as demandas individuais. Dessa forma, este estudo tornou-se relevante devido a capacidade de validar, por meio das respostas obtidas, como o entendimento sobre o assunto pode afetar na tomada de decisões futuras.

\section{REFERÊNCIAS}

ANGULO-RUIZ, F.; PERGELOVA, A. An empowerment model of youth financial behavior. The journal of consumer affairs, v. 49, n. 3, p. 550-575, 2015. Disponível em: http://onlinelibrary-wileycom.ez30.periodicos.capes.gov.br/doi/10.1111/joca.12086/full. doi: 10.1111/joca.12086.

DISNEY, R.; GATHERGOOD, J. Financial literacy and consumer credit portfolios. Journal of Banking \& Finance, v. 37, p. 2246-2254, 2013. Disponível em: http://dx.doi.org.ez30.periodicos.capes.gov.br/10.1016/j.jbankfin.2013.01.013 doi: 10.1016/j.jbankfin.2013.01.013

ENEF - ESTRATÉGIA NACIONAL DE EDUCAÇÃO FINANCEIRA. Educação financeira no mundo. Disponível em: http://www.vidaedinheiro.gov.br/pagina-28no_mundo.html. Acesso em: 12 de Março de 2017.

FRENCH, D.; MCKILLOP, D. Financial literacy and over-indebtedness in low-income household. International Review of Financial Analysis, v. 48, p. 1-11, 2016. Disponível

em: http://dx.doi.org.ez30.periodicos.capes.gov.br/10.1016/j.irfa.2016.08.004. doi: 10.1016/j.irfa.2016.08.004.

GIOFRÉ, M. Financial education, investor protection and international portfolio diversification. Journal of International Money and Finance, v. 71, p. 111-139, $2017 . \quad$ Disponível em: http://dx.doi.org.ez30.periodicos.capes.gov.br/10.1016/j.jimonfin.2016.11.004. doi: 10.1016/j.jimonfin.2016.11.004.

LO PRETE, A. Economic literacy, inequality, and financial development. Economics 
Letters, v. 118, p. 74-76, 2013. Disponível em: http://scihub.cc.ez30.periodicos.capes.gov.br/10.1016/j.econlet.2012.09.029. doi: 10.1016/j.econlet.2012.09.029.

MOUNA, A.; ANIS, J. Financial literacy in Tunisia: Its determinants and its implications on investment behavior. Research in International Business and Finance, v. 39, p. 568-577, 2017. Disponível em: http://scihub.cc.ez30.periodicos.capes.gov.br/10.1016/j.ribaf.2016.09.018. doi: 10.1016/j.ribaf.2016.09.018.

OECD - ORGANIZATION FOR ECONOMIC COOPERATION AND DEVELOPMENT. National Strategies for Financial Education. Disponível em: http://www.oecd.org/daf/fin/financial-

education/nationalstrategiesforfinancialeducation.htm. Acesso em: 13 de Março de 2017.

SAVOIA, J. R. F.; SAITO, A. T.; SANTANA, F. A. Paradigmas da educação financeira no Brasil. Revista de Administração Pública, v. 41, n. 6, p. 1121-1141, 2007.

em:

http://bibliotecadigital.fgv.br/ojs/index.php/rap/article/view/6620/5204.

SILVA, R.; TEIXEIRA, A.; BEIRUTH, A.X. Finanças pessoais e educação financeira: o perfil dos servidores públicos de um munícipio do Centro-Oeste brasileiro. Revista UNEMAT de Contabilidade, v. 5, n. 10, p. 113-136, 2016. Disponível em: http://periodicos.unemat.br/index.php/ruc/article/view/1382/1574.

VAN ROOIJ, M. C. J.; LUSARDI, A.; ALESSIE, R. J. M. Financial literacy, retirement planning and household wealth. The Economic Journal, v. 122, n. 560, p. 449-478, 2012. Disponível em: http://sci-hub.cc/10.1111/j.1468-0297.2012.02501.x. doi: 10.1111/j.1468-0297.2012.02501.x.

VIEIRA, S. F. A.; BATAGLIA, R. T. M.; SEREIA, V. J. Educação financeira e decisões de consumo, investimento e poupança: uma análise dos alunos de uma universidade pública do norte do Paraná. Revista de Administração da UNIMEP, v. 9, n. 3, p. 61-86, $2011 . \quad$ Disponível em: http://www.regen.com.br/ojs/index.php/regen/article/view/345/477. doi: 10.15600/1679-5350/rau.v9n3p61-86. 


\section{Anexo I}

QUADRO 1. Questionário aplicado (adaptado de VIEIRA et al., 2011). 
1) Como você se sente a respeito dos seus conhecimentos para gerenciar seu próprio dinheiro?

a. Nada seguro - Eu gostaria de possuir um nível muito melhor de educação financeira

b. Não muito seguro - Eu gostaria de saber um pouco mais sobre finanças

c. Razoavelmente seguro - Eu conheço a maioria das coisas que eu precisaria saber sobre o assunto

d. Muito seguro - Eu possuo conhecimentos bastante amplos sobre finanças

2) Onde você adquiriu a maior parte dos seus conhecimentos para gerir o seu dinheiro? Preencha as lacunas por ordem decrescente de importância (1 - mais importante, 2 - importância média-alta, 3 - importância média...).

Em casa com a família

De conversas com amigos

Em aulas na universidade

_ De revistas, livros, TV e o rádio

_ De minha experiência prática

\section{GRUPO 02}

3) Muitas pessoas guardam dinheiro para despesas inesperadas. Se Susana e Júlio César têm guardado algum dinheiro para emergências, qual das seguintes formas seria a menos eficiente para o caso deles precisarem do recurso com urgência?

a. Poupança ou Fundos de Investimento

b. Ações ou Dólar

c. Conta-corrente

d. Bens (Carro, moto, imóvel...)

4) Ronaldo e Daniela têm a mesma idade. Aos 25 anos, ela começou a aplicar R\$ $1.000,00$ por ano, enquanto o Ronaldo não guardava nada. Aos 50 , Ronaldo percebeu que precisava de dinheiro para sua aposentadoria e começou a aplicar $\mathbf{R} \$ \mathbf{2 . 0 0 0 , 0 0}$ por ano, enquanto Daniela continuou poupando seus $\mathbf{R} \$ 1.000,00$. Agora eles têm 75 anos. Quem tem mais dinheiro para sua aposentadoria, se ambos fizeram o mesmo tipo de investimento?

a. Eles teriam o mesmo valor, já que na prática guardaram as mesmas somas

b. Ronaldo, porque poupou mais a cada ano

c. Daniela, porque seu dinheiro rendeu por mais tempo a juros compostos.

5) Qual das pessoas pagaria mais em despesas financeiras por ano se elas gastassem a mesma quantia por ano em seus cartões de créditos?

a. Ellen, que sempre paga todo o saldo do cartão de crédito no vencimento.

b. Pedro, que geralmente paga todo o saldo do cartão de crédito no vencimento, mas ocasionalmente paga só o mínimo, quando está sem dinheiro.

c. Luís, que paga pelo menos o mínimo todo mês e um pouco mais quando tem alguma folga.

d. Nanci, que sempre paga o mínimo

6) José ganha $R \$ 1.000,00$ por mês. Paga $R \$ 300,00$ de aluguel e mais $R \$ 200,00$ de alimentação todo mês. Gasta ainda $R \$ 100,00$ em transportes, $R \$ 50,00$ em roupas, $R \$$ 50,00 em remédios e mais $R \$ 100,00$ em pequenas despesas extras. Pretende comprar uma TV que custa R\$ $\mathbf{8 0 0 , 0 0}$. Quanto tempo ele levará guardando recursos para comprar a TV?

a. 2 meses

b. 4 meses

c. 6 meses

d. 8 meses
7) Sexo

a. Masculino

b. Feminino

8) Idade

a. Até 20 anos

b. De 21 a 30 anos

c. De 31 a 40 anos

d. Acima de 40 anos

9) Estado Civil

a. Solteiro

b. Casado/União Estáve

c. Separado/Divorciado

d. Outros

10) Qual a sua faixa de renda mensal líquida pessoal? a. Até $\mathrm{R} \$ 500,00$

b. $R \$ 500,01$ até $R \$ 1.000,00$

c. $R \$ 1.000,01$ até $R \$ 1.500,00$

d. $R \$ 1.500,01$ até $R \$ 2.500,00$

e. Acima de $\mathrm{R} \$ 2.500,00$

11) Qual sua faixa de renda mensal líquida familiar? a. Até $\mathrm{R} \$ 500,00$

b. $R \$ 500,01$ até $R \$ 1.000,00$

c. $R \$ 1.000,01$ até $R \$ 1.500,00$

d. $R \$ 1.500,01$ até $R \$ 2.500,00$

e. $R \$ 2.500,01$ até $R \$ 4.000,00$

f. Acima de $R \$ 4.000,00$

12) Qual o percentual da sua renda pessoal que você destina para os seguintes itens? Assinale as lacunas com o percentual aproximado destinado a cada item.

Despesas Gerais (alimentação, água, luz, telefone,

moradia, plano de saúde, etc.)

Despesas Pessoais (lazer, vestuário, etc.)

Poupança e Investimento

Financiamento e prestações para aquisição de bens

Complemento do orçamento familiar (se você não é a

principal fonte de renda, mas ainda assim ajuda em casa)

Outros. Cite:

13) Qual sua fonte principal de renda?

a. Emprego Formal

b. Emprego Informal

c. Não trabalha

d. Outros.

14) Assinale quais as pessoas que residem com você? Marque mais de uma resposta se for o caso.

Pais

_ Cônjuge/Companheiro (a)

Filhos

Outros

15) Qual o maior grau de escolaridade dos seus pais?

a. Ensino Fundamental Incompleto

b. Ensino Fundamental Completo

c. Ensino Médio Incompleto

d. Ensino Médio Completo

e. Ensino Superior Incompleto

f. Ensino Superior Completo

g. Pós-graduação Completo ou Incompleto 